\title{
THE SENTENCE-FINAL PARTICLES NE AND YO IN SOLILOQUIAL JAPANESE*
}

\author{
Yoko Hasegawa
}

\begin{abstract}
This paper investigates the Japanese sentence-final particles ne and yo as they occur in soliloquy. Because of their pivotal roles in spoken Japanese, these particles have been investigated extensively for decades. However, most previous works have analyzed them solely in terms of communication, invariably assuming the presence of an addressee. In fact, it is not yet widely known that these particles can also occur in soliloquy in which communication with another person is not intended. The present article is the first study to address the significance of ne and yo as they occur in soliloquy and discuss problems associated with hitherto proposed analyses. In order to investigate how communicative and non-communicative intentions influence utterances, an experiment was conducted in which soliloquies of native speakers of Japanese were examined. For ne, this study endorses Takubo and Kinsui's Discourse Management Model. For yo, Inoue's account is vindicated.
\end{abstract}

Keywords: Soliloquy; Sentence-final particles; Ne and yo; Interactional particles.

\section{Introduction}

This paper investigates the Japanese sentence-final particles ne and yo as they occur in soliloquy, i.e. utterances of one's thoughts without addressing, or communicating with, any particular individual. These sentence-final particles reflect the speaker's attitude towards the proposition and/or the interlocutor(s) and play a pivotal role in spoken Japanese. Consequently, they have been investigated extensively for several decades. However, most previous works have analyzed these particles solely in terms of communication, invariably assuming the presence of an addressee who is distinct from the speaker. In fact, it is not yet widely known that these particles can also occur in soliloquy in which communication with another person is not intended. The present article is the first study to address the significance of ne and yo as they occur in soliloquy and discuss problems associated with hitherto proposed analyses.

Because the primary function of language is arguably communication, one might wonder why we should investigate such a non-canonical situation as soliloquy. In this respect, it is important to acknowledge that language is not only an instrument of communication, but also an instrument of thought. The research exploring language as a

\footnotetext{
* I would like to thank Yukio Hirose, Wesley Leonard, Ashlyn Moehle, Russell Lee-Goldman, and the anonymous reviewer of Pragmatics for their comments and suggestions. This study was supported by a grant form the Center for Japanese Studies, University of California, Berkeley.
} 
vehicle of communication is enormous, and our knowledge of various linguistic devices for effective communication has advanced significantly in recent decades. By contrast, in empirical research, exploration of language as a tool for thinking is scarce, with the study of private speech in psycholinguistics a notable exception. Analyzing language used in such a non-canonical setting as soliloquy can be inspirational. By providing valuable data for examination of how, and possibly why, linguistic structures differ between communicative and non-communicative settings, studies of soliloquy will foster progress in understanding the nature of language and its use.

Japanese is especially appropriate for this line of inquiry because its native speakers appear to have an intuitive awareness of the soliloquy mode of discourse. Therefore, although soliloquy itself has rarely been a focus of attention, many researchers on various linguistics topics have presented certain utterances as a priori soliloquies, e.g. Uyeno 1972; Kuroda 1979/1992; Cheng 1987; Maynard 1991, 1993; Nitta 1991; Hirose 1995; Usami 1995; Ono and Nakagawa 1997; Suzuki 1997; Washi 1997; Moriyama 1998; Okamoto 1999; Izuhara 2003; Shinzato 2004, to name a few. Most native speakers of Japanese consider, for example, such phrases as $A$, soo nan daa 'Oh, I see' to be soliloquy. ${ }^{1}$ By contrast, speakers of English usually do not have the same clarity of distinction. When asked whether a phrase such as $\mathrm{Oh} / \mathrm{Ah} / \mathrm{Huh}$, I see sounds like dialog or soliloquy, their answers vary considerably.

This difference is likely due to the fact that the soliloquy mode of discourse has to some extent been grammaticized in Japanese, but not in English. Understandably, therefore, soliloquy appears to play a more significant role in Japanese, although it certainly has pragmatic significance in both languages.

Some researchers consider that speech and thought are always dialogic. That is, the speaking-self and the talked-to-self necessarily exist even in soliloquy, and that they invariably mirror normal conversational exchanges. Bakhtin's (1984) dialogism is an example of this conception, in which all human discourse is recognized as a complex thread of dialogic interrelations with other utterances. He writes:

"Each person's inner world and thought has its stabilized social audience that comprises the environment in which reasons, motives, values and so on are fashioned ... In point of fact, word is a two-sided act. It is determined equally by whose word it is and for whom it is meant. As a word it is precisely the product of the reciprocal relationship between speaker and listener, addresser and addressee. Each and every word expresses the 'one' in relation to the 'other'. I give myself verbal shape from another's point of view of the community to which I belong." (p.86)

This idea of dialogism is consistent with Vygotsky's (1934/1986) thesis of the social origins of private speech. ${ }^{2}$

${ }^{1}$ Other examples typically interpreted as soliloquy by native speakers are: Hontoo daroo ka 'I wonder if it's true', Naruhodo ne 'That makes sense', Ganbaru zo 'I'll make it, no matter what'.

2 The study of soliloquy was originated by Piaget (1923/2002), who observed kindergarten children talking to themselves as if thinking aloud. He named this phenomenon egocentric speech, arguing that it was due to young children's cognitive immaturity. That is, while communicating with others, they are unable to take the addressee's perspective into consideration, and thus, their utterances are often incomprehensible to others. Vygotsky interpreted the same phenomenon in a totally different manner. For him, the developmental direction is not from egocentric and autistic utterances to social, communicative utterances, as Piaget had claimed, but rather, from social speech to subvocalized inner speech, i.e. to thoughts. In other words, Vygotsky argues, young children often think aloud because they have not yet learned to control their thoughts internally. Today, Vygotsky's perspective is commonly referred to as 
However, even if soliloquy is essentially dialogic, there may nevertheless be profound differences between these two modes of discourse. If the speaker and addressee are identical (i.e. talking to oneself), there is no gap or discrepancy in their beliefs, assumptions, and relevant background knowledge; therefore, the speaker does not have to consider knowledge and perspective that are distinct from his/her own. As a result, the information structure of soliloquy should be expected to differ from normal dialogic conversations. As a further example, we could easily speculate on the absence of linguistic politeness in soliloquy because the speaker does not need to consider the possibility of threatening the addressee's self-esteem (i.e. face).

As mentioned above, ne and yo have been investigated exclusively in terms of their communicative functions. Therefore, it is of particular interest to investigate how communicative and non-communicative intentions influence their usage. For this purpose, an experiment was conducted in which soliloquies of native speakers of Japanese were examined. The present study reports an analysis of $n e$ and yo of these experimental data and discusses the findings in order to suggest further directions for investigation in this promising research area. The organization of the balance of this paper is as follows: Section 2 provides a brief outline of hitherto proposed analyses of $n e$ and yo, Section 3 explains my experiment design and lists occurrences of sentence-final particles as well as sample utterances with ne or yo, Section 4 discusses the experiment results and their implications, and Section 5 concludes the paper.

\section{Previous studies}

$\mathrm{Ne}$ and yo have usually been described as occurring only in the presence of an addressee who is an individual distinct from the speaker him/herself. Commonly, $n e$ is said to be used when the speaker assumes that $\mathrm{s} / \mathrm{he}$ and the addressee have the same status regarding the knowledge of or belief about the piece of information being conveyed, whereas yo is used when different cognitive statuses are assumed. Uyeno (1971: 96), for example, points out that $n e$ in (1) is used when the speaker expects the addressee, like $\mathrm{him} /$ herself, to be aware of the information, whereas yo is used when the speaker expects the addressee to be unaware of it.

(1) Sonna koto wa atarimae
such thing TOP matter of course
'That goes without saying.'

The functions of $n e$ include requesting confirmation and seeking or showing agreement. These usages are exemplified below, taken from Ohso (1986):

$$
\begin{aligned}
& \text { A: Kyoo wa kin'yoobi desu ne. (requesting confirmation) } \\
& \text { today TOP Friday COP } \\
& \text { 'Today is Friday, isn't it?' } \\
& \text { B: Ee, soo desu. } \\
& \text { yes so COP }
\end{aligned}
$$

\footnotetext{
private speech.

${ }^{3} \mathrm{COP}=$ copula $; \mathrm{GEN}=$ genitive $; \mathrm{NMLZ}=$ nominalizer; $\mathrm{NOM}=$ nominative; $\mathrm{Q}=$ interrogative $; \mathrm{QUOT}=$ quotative; $\mathrm{SFP}=$ sentence-final particle; $\mathrm{TOP}=$ topic
} 
'Yes, that's right.'

(3) A: Kyoo wa kin'yoobi desu ne. (seeking agreement)

today TOP Friday COP

'Today is Friday, isn't it?'

B: Soo desu ne. Yatto isshuukan owarimasu ne.(showing agreement)

so $\mathrm{COP}$ finally a-week ended

'Yes. Finally, the week is over.'

However, as Kato (2001: 33-34) points out, this analysis cannot account for the use of ne in (4) nor for the use of yo in (5).
A: Juubun ja nai desu ka.
enough not COP Q
'It's enough, isn't it?'
B: Watashi to shite wa, mitomeraremasen $\boldsymbol{n e}$. for-me TOP cannot-agree
'I can't agree with you.'

(5) (The interlocutors are seeing the rain together.)
Yoku furu ne/yo.
often fall
'It's raining again.'

Kamio (1994) also characterizes ne and yo while presupposing the presence of an addressee: $n e$ is used when the information falls within the addressee's territory (6a), but yo is used when it falls within the speaker's territory (6b).
a. Kimi no imooto-san, uta ga umai ne. you GEN sister song NOM is-good-at 'Your sister sings well.'
b. Kushiro wa samui yo. (The speaker is a resident in Kushiro.) TOP cold
'It's cold in Kushiro.'

Cook $(1990,1992)$ points out that ne is not limited to agreement on propositional content, and that it frequently signals an affective common ground between the speaker and the addressee, requiring the addressee's cooperation. As such, $n e$ is often used when the speaker must convey negative information, as shown in (7):

(7) Oshokuji no tokini mama shikaritakunai kedo nee. Hitoshi no meal GEN time mother not-want-to-scold but GEN

\begin{tabular}{|c|c|c|c|c|}
\hline $\begin{array}{l}\text { ono } \\
\text { hat }\end{array}$ & $\begin{array}{l}\text { tabekata } \\
\text { way-of-eatin }\end{array}$ & $\begin{array}{l}n i w a \\
\text { TOP }\end{array}$ & $\begin{array}{l}\text { moo } \\
\text { no-more }\end{array}$ & \\
\hline
\end{tabular}

'I don't want to scold you at dinner time but ... I can't forgive you for the manner in which you eat any more.'

Izuhara (2003) compares ne, yo, and yone. She argues that they are all used to persuade the addressee to adopt the same cognitive state as that of the speaker. 
However, these particles differ with respect to how they accomplish such a task. According to Izuhara, yo is used to change the addressee's cognition by asserting the speaker's own thought; yone is used to achieve the same goal by confirming whether or not the speaker's cognitive stance is shared by the addressee; ne is used to do so by requesting agreement without necessarily asserting the speaker's own epistemic stance. Because all of these particles request some modification in the addressee's cognition, Izuhara contends, they may sometimes emit an obtrusive tone. Because of this fact, many speakers avoid these particles when speaking to their superiors, e.g. (8):
a. Denwa desu kedo/yo.
telephone COP but/SFP
'You have a phone call.'
b. Ashita irasshaimasu $\mathrm{ka} /$ ne.
tomorrow come $\quad \mathrm{Q} / \mathrm{SFP}$
'Will you come tomorrow?'

Katagiri $(1995,2007)$ contends that ne and yo contribute to coordination of dialogue by indicating the speaker's state of acceptance/nonacceptance regarding the information expressed with the utterance. $Y o$ is used to present the information as already accepted by the speaker, whereas ne indicates that the information has not yet been thoroughly accepted. The addressee can use such information subsequently to determine for him/herself whether or not to accept.

This section has provided a brief outline of how ne and yo have been analyzed in the linguistics literature. We now turn to our experiment data.

\section{The experiment}

Twenty-four subjects ( 8 males and 16 females, all native speakers of Japanese) participated in this soliloquy experiment. For 10-15 minutes, each spoke aloud his or her thoughts while alone in an isolated room. They were instructed not to speak to an imaginary person, but rather to verbalize forthrightly whatever came into their consciousness. Their soliloquies were recorded and subsequently transcribed.

All subjects were aware that they were being recorded. This procedure might be criticized as being too far removed from genuine, spontaneous soliloquy. However, the primary interest of this experiment is to eliminate the addressee as a person distinct from the speaker him/herself. In this regard, naturalistic and artificially induced soliloquies are not likely to differ significantly.

A total of 3,042 sentences or sentence fragments were obtained. ${ }^{4}$ Of those, 1,483 utterances $(48.8 \%)$ ended in one of the sentence-final particles. Although not directly comparable, Maynard (1997: 88) reports that in her 60 minute conversation data, what she categorizes as interactional particles occurred approximately once every 2.5 phrase-final positions $(40.0 \%) .^{5}$ I hypothesize that sentence-final particles occur

\footnotetext{
${ }^{4}$ Many utterances in my data consist of sentence fragments. To determine where the boundary between sentences and/or sentence fragments are located, a procedure was developed based on syntactic considerations, the duration of silence, and intonation contours.

5 Maynard (1997: 87) distinguishes two categories of Japanese particles: those that play a grammatical function and those expressing the speaker's judgment and attitude toward the conveyed
} 
equally frequently in interactional as well as soliloquial discourse.

Table 1 summarizes the occurrences of the sentence-final particles in our experimental soliloquy data. The final vowel of the particles can be elongated; these short and long variations are not counted separately. (Subj: subject; ${ }^{6}$ UT: utterance total)

Table 1

Frequencies of sentence-final particles in the soliloquy data

\begin{tabular}{|l|l|l||l|l|l|l|l|l|l|l|l|l|}
\hline Subj & Sex & UT & na & kana & kena & kekana & yona & ne & kane & kene & yone & ka \\
\hline \hline A & M & 76 & 14 & 8 & & & & 7 & & & 1 & 6 \\
\hline B & F & 68 & 7 & 12 & & & & 8 & & & & 4 \\
\hline C & F & 122 & 9 & 28 & 2 & 1 & & 3 & & & & 6 \\
\hline D & F & 161 & 20 & 27 & & & & 26 & & & 7 & 9 \\
\hline E & M & 196 & 19 & 37 & & & 10 & 49 & 5 & 1 & 57 & 4 \\
\hline F & F & 97 & 4 & 11 & & & & 3 & & & & 3 \\
\hline G & F & 76 & 15 & 25 & & & & & & & & 3 \\
\hline H & F & 188 & 8 & 9 & 2 & & & 50 & 5 & & 5 & 9 \\
\hline I & F & 175 & 11 & 2 & & & 3 & & & & & 2 \\
\hline J & F & 117 & 4 & 17 & & & & 17 & & & & 4 \\
\hline K & F & 172 & 2 & 22 & 1 & & & 3 & & & 4 & 5 \\
\hline L & M & 162 & 31 & 24 & & & 1 & 10 & & & 3 & 18 \\
\hline M & F & 90 & 6 & 25 & 1 & & & 6 & & & 1 & 5 \\
\hline N & M & 102 & 4 & 6 & & & & 4 & & & 1 & 17 \\
\hline O & F & 124 & 12 & 13 & & & 2 & 11 & & & 2 & 1 \\
\hline P & F & 119 & 36 & 25 & & & 1 & 36 & & & & 13 \\
\hline Q & M & 172 & 34 & 24 & & & 1 & 34 & & & 6 & 14 \\
\hline R & M & 35 & 1 & & & & & 2 & & & 1 & 1 \\
\hline S & F & 127 & 6 & 7 & & & & 5 & 1 & & 2 & 14 \\
\hline T & M & 105 & 9 & 20 & & & 4 & 11 & 2 & & 17 & 9 \\
\hline U & M & 144 & 26 & 31 & & & 2 & 5 & & & & 12 \\
\hline V & F & 145 & 7 & 17 & & & 3 & & & & 5 & 10 \\
\hline W & F & 142 & 2 & 19 & & & & 10 & & & 2 & 3 \\
\hline X & F & 127 & 3 & 16 & & & & 17 & & & 13 & 4 \\
\hline Total & & 3,042 & 290 & 425 & 6 & 1 & 27 & 317 & 13 & 1 & 127 & 176 \\
\hline$\%$ & & & $9.5 \%$ & $14.0 \%$ & $0.2 \%$ & $0.0 \%$ & $0.9 \%$ & $10.4 \%$ & $0.4 \%$ & $0.0 \%$ & $4.2 \%$ & $5.8 \%$ \\
\hline
\end{tabular}

\begin{tabular}{|l||l|l|l|l|l|l|l|l|l|l|l|l|}
\hline Subj & $y o$ & $k a y o$ & $y a$ & $w a \downarrow$ & $w a \uparrow$ & $k e$ & $s a$ & $d e$ & $n o$ & kashira & Total & $\%$ \\
\hline \hline A & & & 2 & & & & & & & & 38 & $50.0 \%$ \\
\hline B & & & & & & 1 & & & & 2 & 34 & $50.0 \%$ \\
\hline C & & & & & & 1 & & & & & 50 & $41.0 \%$ \\
\hline D & & & & & 1 & & & & & 3 & 93 & $57.8 \%$ \\
\hline E & & & & & & 3 & & & & & 185 & $94.4 \%$ \\
\hline F & & & & & & & & & & 2 & 23 & $23.7 \%$ \\
\hline G & & & & & & & & & & & 43 & $56.6 \%$ \\
\hline H & & & 3 & 2 & & 1 & & & 1 & & 95 & $50.5 \%$ \\
\hline I & & & 1 & 11 & & 1 & & & 1 & & 32 & $18.3 \%$ \\
\hline J & & & & & & 1 & & & 1 & & 44 & $37.6 \%$ \\
\hline K & & & & & & 1 & & & 1 & & 39 & $22.7 \%$ \\
\hline L & & & 1 & & & 2 & & & 1 & & 91 & $56.2 \%$ \\
\hline
\end{tabular}

information and/or the addressee. Maynard does not seem to consider $k a$ to be interactional.

${ }^{6}$ Most of the subjects are native speakers of the Tokyo dialect. Speakers of other dialects are: Subject B (Sapporo), F (Kyoto), G (Fukuoka), H (Nagasaki), I (Okayama), P (Kyoto), Q (Mie), S (Kagawa). 


\begin{tabular}{|l||l|l|l|l|l|l|l|l|l|l|l|l|}
\hline $\mathrm{M}$ & & & & & & 4 & & & & & 48 & $53.3 \%$ \\
\hline $\mathrm{N}$ & 2 & 1 & 1 & & & 2 & & & 1 & & 39 & $38.2 \%$ \\
\hline $\mathrm{O}$ & & & & & & 6 & 2 & & 1 & & 50 & $40.3 \%$ \\
\hline $\mathrm{P}$ & & & & & & 1 & 1 & & & & 113 & $95.0 \%$ \\
\hline $\mathrm{Q}$ & & & & 4 & & & 3 & 4 & & & 124 & $72.1 \%$ \\
\hline $\mathrm{R}$ & & & & & & & & & & & 5 & $14.3 \%$ \\
\hline $\mathrm{S}$ & & & 1 & 2 & & & & & & 2 & 40 & $31.5 \%$ \\
\hline $\mathrm{T}$ & & & & & & & & & & & 72 & $68.6 \%$ \\
\hline $\mathrm{U}$ & 1 & & & & & & & & & & 77 & $53.5 \%$ \\
\hline $\mathrm{V}$ & 1 & & 2 & 3 & & 5 & & & & & 53 & $36.6 \%$ \\
\hline $\mathrm{W}$ & & & 1 & & & 2 & & & 1 & & 40 & $28.2 \%$ \\
\hline $\mathrm{X}$ & & & & & & 1 & & & 1 & & 55 & $43.3 \%$ \\
\hline \hline Total & 4 & 1 & 12 & 20 & 3 & 32 & 6 & 4 & 9 & 9 & 1,483 & $100.0 \%$ \\
\hline & $0.1 \%$ & $0.0 \%$ & $0.4 \%$ & $0.7 \%$ & $0.1 \%$ & $1.1 \%$ & $0.2 \%$ & $0.1 \%$ & $0.3 \%$ & $0.3 \%$ & & \\
\hline
\end{tabular}

Sample utterances containing ne or yo are provided in (9).

a. $\quad$ e $(317$ occurrences, $10.4 \%)$

Asoko no toshokan, ookikute kireide ii ne.

there GEN library large clean good

'That library is large and clean, so it's good.'

b. $\quad$ yo $(4,0.1 \%)$

Dango urenai yo,
not-sell $\quad \begin{gathered}\text { definitely } \\ \text { 'Dango [sweet dumplings] won't sell, definitely.' }\end{gathered}$

Surprising in my data is the frequent use of ne. It occurs by itself 317 times $(10.4 \%)$, and when combined with kane, kene, and yone, its occurrence rises to 458 times, or in $15.1 \%$ of all utterance tokens. ${ }^{7}$ This frequent use of ne was unpredicted because ne and yo have been characterized almost exclusively in terms of communication, necessarily assuming the presence of an addressee, as summarized in Section 2.

\section{The data analysis}

My soliloquy data include abundant samples of $n e$ and suggest that an essential function of $n e$ is independent of the alleged (speaker's assumption of) shared knowledge with the addressee, the interlocutors' information territories, an affective common ground between them, or the speaker's signaling how the addressee ought to process the information in question. Yo is commonly said to indicate the speaker's assumption that $\mathrm{s} /$ he and the addressee possess variant cognitive statuses regarding the information at hand. Unlike $n e, y o$ is extremely rare in soliloquy. This contrast suggests that, whatever the essential functions of these particles are, that of ne is significantly more useful in

7 Whether kane, yone, and kene should be treated as single particles or combinations of two particles is controversial. Saigo (2006: 27), for example, considers them to be separate particles, with yo falling within the pragmatic scope of $n e$ in yone. Although tentative, I consider yone to be a variation of $n e$, rather than a succession of yo and ne, because all occurrences of yone in my data can be substituted with ne without significant changes in the nuance of the utterance. I admit, however, that ne and yone are not identical. This topic certainly merits thorough investigation. 
thinking (vis-à-vis communicating) than that of $y o$.

\subsection{Ne}

The only proposed analysis that can be extended to accommodate soliloquial $n e$ is Takubo and Kinsui's (1997) and Kinsui and Takubo's (1998) Discourse Management Model. Although they assume that ne is used only interactionally, i.e. in the presence of an addressee, they nevertheless attempt to explain its function without recourse to an addressee's assumed knowledge about a given topic. To this end, they posit a level of representation that works as a cognitive interface between speech forms and the speaker's knowledge stored in his/her memory, which is conceived as a database in their model. This interface is analogous to a buffer in a computer, i.e. special memory used to temporarily store input or output data, and is divided into two psychological domains: The direct experience domain (D-domain) and the indirect experience domain (I-domain).

At the beginning of each discourse, information about the discourse situation (a part of direct experience) and general information that the speaker considers relevant to the coming discourse stored in his/her permanent memory become highlighted, and indices of, or pointers to, such data are temporarily stored in the D-domain. At the same time, a unique I-domain is constructed specifically for the purpose of each discourse. In order to speak, Takubo and Kinsui argue, the speaker interprets information in the D-domain into conceptual terms and stores it in the I-domain. (It is the indices that are stored in these domains, but for the sake of exposition, the idea is simplified and stated as if information itself is stored in them.)

Information obtained by one's direct experience and information obtained by some indirect means, e.g. via hearsay or inference, are fundamentally different. This difference is significantly manifested in Japanese in such areas as referring expressions (e.g. the use of proper noun vs. third person pronoun), demonstratives, and sentence-final particles (Takubo and Kinsui 1997; Kinsui and Takubo 1998). To envision this difference, consider the case in which you experientially know the referent of some linguistic expression. You will realize that it can theoretically be described in an infinite number of ways. For example, if someone asks me about my mother, I can describe her in terms of her age, appearance, health, interests, skills, etc. By contrast, indirectly obtained information is inevitably conceptual, or linguistic (i.e. information conveyed by some linguistic means). For example, if someone says to me $M y$ high-school friend Alice called me yesterday, I acquire the information that a person named Alice (conventionally a female name), who attended the same high school as the speaker, telephoned him/her yesterday, but not much more. The D-domain temporarily stores indices of data obtained experientially and stored permanently in one's memory, whereas the I-domain temporarily stores data obtained by indirect means during each discourse.

In Takubo and Kinsui' theory, the act of speaking involves manipulation of indices in the D-domain and I-domain by means of registering, searching, computing, inferring, etc., and sentence-final particles are markers for operations being carried out on the database. The essential function of ne is matching of information between two sources, "as a marker when the speaker is in the process of incorporating assumptions from the I-domain into the D-domain. It is a marker for an on-going verification 
procedure" (Takubo and Kinsui 1997: 754). For example, when the speaker tries to confirm that the addressee is John Smith, this proposition is in the speaker's I-domain because it is yet to be verified. If there is enough evidence, the speaker concludes that the proposition is true, at which point s/he may incorporate it into the $\mathrm{D}$-domain.

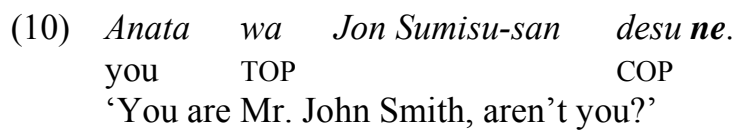

(10') D-domain: evidence for the identity of the hearer in the speaker's memory I-domain: the proposition to be verified = the addressee is John Smith

The two sources for matching may be two different persons, or different data points within a single person, e.g. old and new information. For example, in conversation (11), Speaker B first looks at his/her watch and finds that the little hand is pointing to ' 7 ', and then s/he judges that the watch is accurate so that what it tells is the correct time (1997: 752).

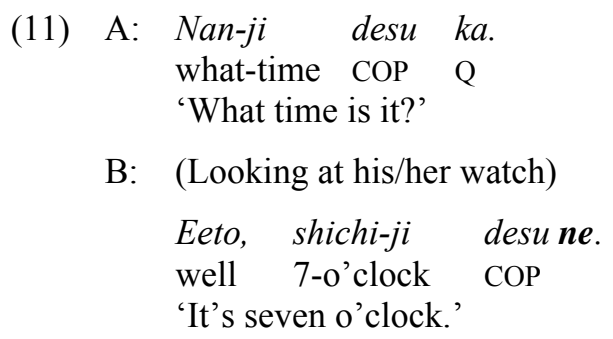

This explanation captures well the different nuances between the utterances with and without $n e$ in B's response in (11). Without ne, the utterance would merely indicate that the time is seven o'clock, without implying any type of computation or confirmation on the part of the speaker.

If matching between two sources is unlikely involved, the use of ne will sound anomalous, e.g. (12):

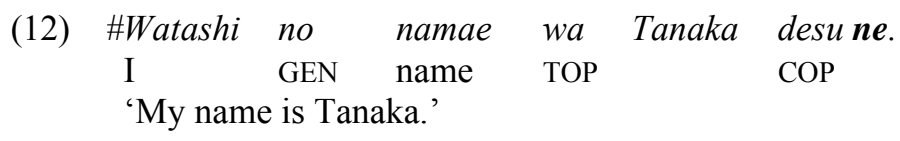

Following my soliloquy experiment, I have found Takubo and Kinsui's hypothesis quite plausible. Monitoring one's own thoughts without verbalizing them is virtually impossible, because in our consciousness, thoughts (frequently as mental imagery, i.e. quasi-perceptual experiences) appear and disappear rather quickly. Subvocalizing them as inner speech helps one think coherently, but this help is inadequate when the thoughts become complex. In such a case, the act of soliloquy improves the thought process significantly, and, of course, writing (i.e. fixing, or immobilizing thoughts) is better yet. The act of soliloquizing slows thinking as though anchoring transient thoughts/images to the cognitive ground by words. Such anchored thoughts can then undergo various manipulative processes as Takubo and Kinsui conjecture. Without such manipulation, coherent discourse is deemed impossible. Monitoring his own soliloquy, one of my experiment subjects said the following 
passage, which illustrates the transient nature of thoughts:

(13) Hitorigoto-tte tashikani muchakucha da ne. Jibun ga miteru. Utsumuite kangaeteru. Muchakucha da. Taishite hitorigoto to kawannai kamo na, futsuu ni itteru koto mo. Hontoni muchakucha kamo shinnai ne. Un, muchakucha da. Aa, sake ga nomitai. Setsumeetekini naru to, donna daroo. Eeto, unto, denwa no yoko ni oitearu tsubo mitai no wa, hijooni tokkuri ni niteite. Tokkuri? Un, nantettakke. Kekkoo wasureru mon da ne. Eego ga, eego ga zenzen damena warini, nihongo ga dete konai. Eeto, nan dakke. Eeto, aa, dame da. Omoidasenai. Tonikaku, nihonshu ga nomitai kamo shirenai.

'Self talk is certainly messy. I'm watching myself. Looking down and thinking. Absurd. But it may not be different from my normal speech. My normal speech may be jumbled as well. Yeah, jumbled. Well, I want to drink sake. How will it be if I explain something? Well, hmm, the pot or something next to the telephone looks like tokkuri [a sake bottle] ... Tokkuri? Well, what do you call it? I've forgotten a lot indeed. Poor in English, and losing Japanese. Well, what was it? Hmm, no, I can't. I can't remember it. Well, I might want some Japanese sake.'

To recapitulate, Takubo and Kinsui contend that ne and yo, among other devices, are directive monitoring devices useful in information processing on the part of the speaker. Therefore, their model does not rely on assumed knowledge held by the addressee. When the addressee detects the speaker's self-monitoring device, however, s/he can infer the ongoing progress of the speaker's internal information processing and can plan or make an appropriate move. Takubo and Kinsui emphasize that such perlocutionary effects result from pragmatic (Gricean) inferences and are not semantically encoded in $n e$ and yo.

This idea of matching seems to apply to most occurrences of ne in our soliloquy data. As shown in (14), ne occurs frequently with (i) such adverbials as yappa/yappari 'as expected, of course', sasuga 'as might be expected', igaito 'contrary to expectation', soo ieba 'speaking of that', naruhodo 'reasonably, that explains why something is in such a state', jissai 'actually', (ii) the experiential demonstrative are 'that', (iii) a conditional clause, and (iv) other kinds of comparison, such as mukashi no 'old one'. These expressions indicate that the speaker has compared the current situation with a piece of information in his/her permanent memory.

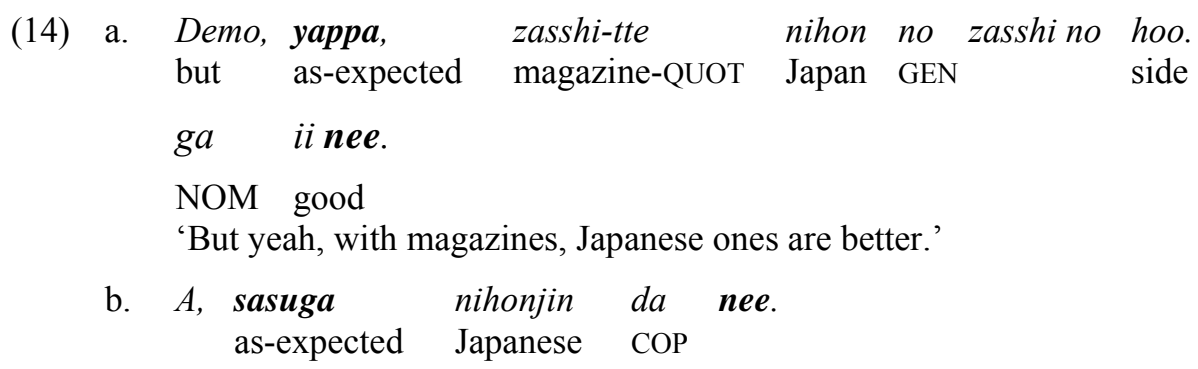

${ }^{8}$ It is frequently said that are 'that (distal)' is used to refer to an entity that the speaker knows experientially, whereas sore 'that (medial)' indicates that the speaker's knowledge about the entity is conceptual. 
'Oh, that's Japanese all over.'

c. Hee, naruhodo ne.

oh understandable

'Oh, that makes sense.'

d. Maa, ato, konaida, sooya, are wa mukatsuita ne. well and the-other-day yes that TOP felt-sick

'Well, and, sometime ago, yes, that made me mad.' $\begin{array}{lllll}\text { e. Shooko-chan ni kiitara, wakaru kamo } & \text { shirenai } \\ & \text { to if-ask find } & \text { not-know }\end{array}$

'If I ask Shoko, I might be able to find out about her.'

f. Kore natsukashii ne. this nostalgic

'It reminds me of the old days.'

Furthermore, ne frequently follows $\operatorname{sh} i$, mon(o), or kara and indicates some sort of reasoning, as in (15). ${ }^{9}$

$\begin{array}{lllllll}\text { a. Hitorigoto, } & \text { moto-moto } & \text { zen-zen } & \text { iwanai } & \text { kedo. } & \text { Ruumu-meeto } & \text { mo } \\ \text { soliloquy } & \text { naturally } & \text { not-at-all } & \text { not-say } & \text { but } & \text { roommate } & \text { also } \\ \text { iru shi ne, } & \text { heya } & \text { ni. } & & & & \\ \text { exist } & \text { room } & \text { in } & & & & \end{array}$

'I never really talk to myself. And I have a roommate too - in the same room, so ...'

b. Natsuyasumi gurai da mon ne, soo iu koto dekin no. summer-break about COP such thing able-to-do NMLZ 'It's only during summer vacation I can do things like that, so ...'
c. A, soo ieba, baito shinaito naa. Kane nai kara nee. oh so if-say side-work must-do money not-exist because 'Oh, that reminds me, I've got to work. Because I don't have money.'

Therefore, Takubo and Kinsui's contention that ne is a monitoring device for the speaker, rather than for the addressee, seems valid in soliloquy.

However, as many researchers claim, the primary function of ne in dialogue seems to establish and/or maintain sharing of information with the addressee (cf. Section 2). A question naturally arises here is as to whether or not these two functions are distinct. Or, does one derive from the other? We will now turn to children's language acquisition, which should provide direction for this problem.

Children acquire their first group of sentence-final particles - yo, no, and ne in that order - between one and a half and two years of age, around the time when they start producing two-word utterances (Okubo 1967: 84). Reporting that many early instances of ne follow partial repetition of adult utterances, Clancy (1986: 429) conjectures, "Such repetitions may serve as a kind of prototypical case of shared

9 These three particles are frequently used to express reasons. Shi 'and' is a conjunctive particle that is used as a sentence-final particle as well (cf. Teramura 1984; Shirakawa 2001). Mon(o) 'thing' is originally a formal noun (i.e. a noun used to form a grammatical structure) that can appear in sentence-final position (cf. Teramura 1982: 297-305; Tsubone 1996). Like shi, the conjunctive particle kara 'because' frequently ends a sentence (cf. Iwasaki 1995; Shirakawa 1995). 
information, with mother and child repeating and agreeing with each other's utterances." $\mathrm{Ne}$ can also occur with information which is not available to the addressee; in this case, the child seeks to secure the addressee's acceptance of the information or speech act. "Ne is often used with requests, apologies, and in imparting information which the listener may not be pleased to hear, in an attempt to convey a sense of fellow-feeling, reduce any negative impact, and gain the listener's compliance" (ibid.), e.g. Gomen ne 'I'm sorry'.

Watamaki (1997) hypothesized that if phaticity (i.e. to establish, prolong, or discontinue communication, cf. Jakobson 1960/1987) were the primary function of $n e$, then children with autism would not be able to use it as shrewdly as nonhandicapped children do. Autistic children are generally believed to be unable to learn smooth social interaction and communication because they lack a theory of mind, which refers to the ability to attribute different mental states to oneself and to others, and to use such differentiation to infer others' intentions as well as to predict their future actions.

Watamaki compared one-hour speech samples of a six-year-old autistic boy, a five-year-old developmentally-challenged boy, and a nonhandicapped girl when she was between 18 months and three years of age. (The girl's data were derived from Okubo 1967). The autistic child rarely used interactional particles and never used ne. Given that $n e$ is the most commonly used particle among nonhandicapped adult speakers (Kokuritsu Kokugo Kenkyujo 1955: 118), its total absence in this autistic subject's speech is astonishing.

To sum up, children typically acquire ne very early in their language development and use it frequently. By contrast, autistic children, who have communication difficulties, are not likely to acquire its use until very late. These facts support Vygotsky's theory of social origins of language (cf. Section 1). Children seem to acquire $n e$ first as an interactional and communicative marker; therefore, it is not well learned by those who have communication deficiency. Normally, children then abstract out $n e$ 's matching function and begin to use it to monitor and regulate their own thoughts. The actual mechanism of this transition surely awaits empirical research.

\subsection{Yo}

Compared with ne (317 occurrences, or $10.4 \%$ of all utterances), yo is extremely rare in soliloquy; in our experiment only four instances by itself $(0.1 \%)$ and once as in kayo. In Maynard's (1997: 88) 60-minute conversation data, on the other hand, ne and yo occurred 364 and 128 times, respectively (at an approximate ratio of 3:1). These extremely biased distributions between dialog and soliloquy may shed some light on the nature of these two particles.

First, let us examine the five tokens of yo in the data. During one subject's recording, his cell phone rang. After hanging up, he said with a low tone on yo:

(16) Machigai denwa kayo. Kimu-tte dare da yo.

wrong telephone QUOT who COP

'Wrong number? Who's Kim?'

Another subject was talking about his experience of attending a job fair held in Boston, Massachusetts, as shown in (17). This yo sounds a little peculiar to me, however. 


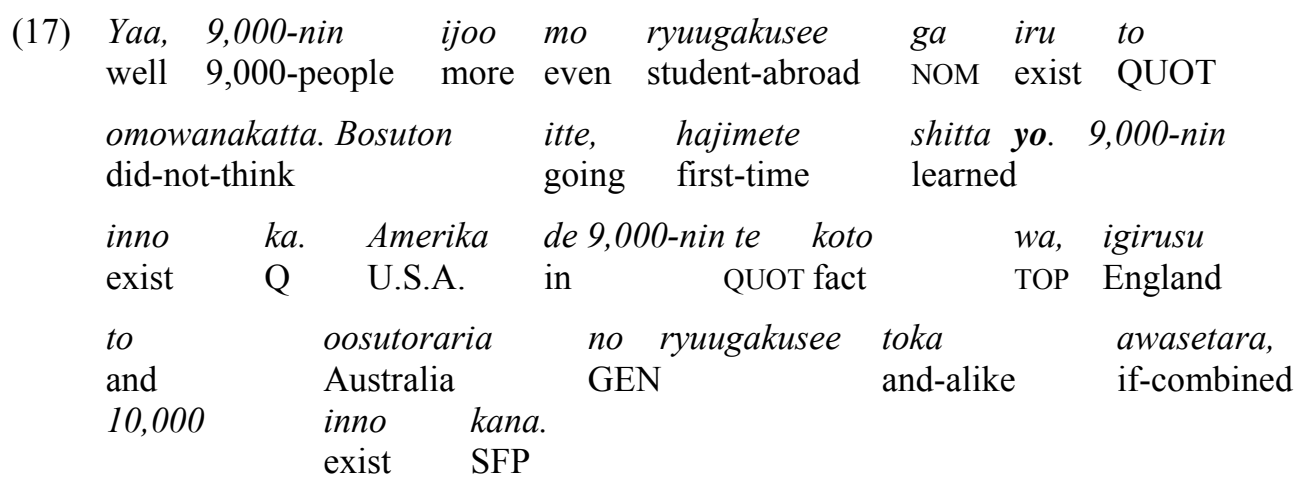

'Well, I never imagined there are more than 9,000 students from Japan. I learned it in Boston. 9,000! If there are 9,000 in the U.S., there may well be 10,000 if those in England and Australia are combined.'

Another subject was thinking about a Japan festival that his group was going to host. He talked about room decoration, activities including games, and food they would serve.

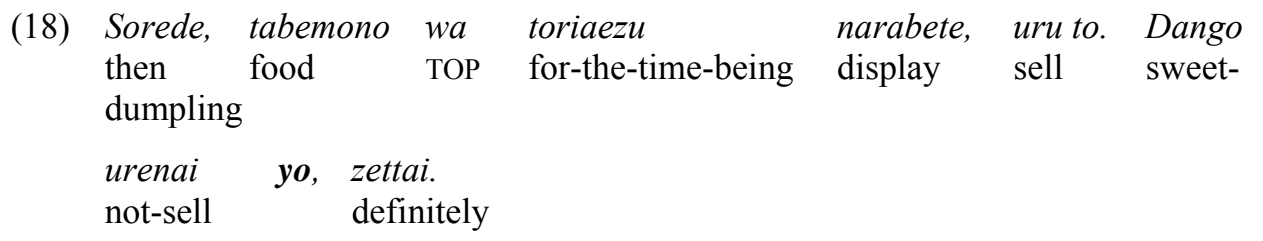

'Then, for the time being, we'll display the food for sale. Dango sweet dumplings won't sell, definitely.'

At first glance, yo seems to occur in soliloquy when the speaker is reproving himself or expressing disgust. Both utterances in (16) are in interrogative form, but the conveyed nuance is annoyance, similar to an effect of rhetorical questions. To support this hypothesis, I provide the following constructed examples, which surely sound natural soliloquy to native speakers of Japanese.
(19) a. Konna koto yattetara, hi ga kurechau yo. this-kind-of-thing if-do day NOM end 'If I'm caught up in things like this, the day will pass me by.'
b. Mata aitsu da yo. again that-guy COP 'Oh, that guy again!'

However, counterexamples can be readily identified; (20) is the fifth and final example of yo in my soliloquy data. The subject had made double hotel reservations and was thinking about which one to cancel. Here, yo does not add a negative nuance.

(20) Un, yasui hoo ga ii wa . A, demo, chooshoku haitterunda-kke. well cheap side NOM good oh but breakfast is-included

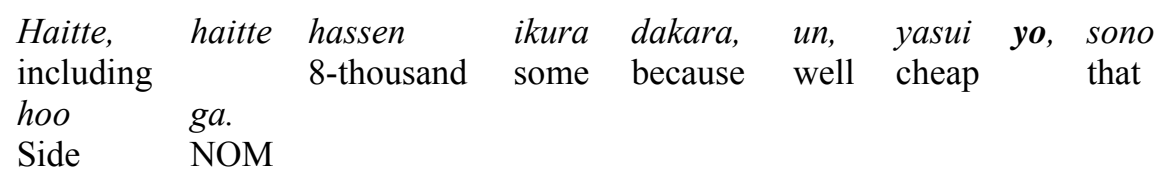


'Well, the cheaper the better. Oh, but this one includes breakfast. It's a little over 8,000 yen including breakfast. So, it's cheaper.'

Takubo and Kinsui define the function of yo as a marker for setting up a proposition in the I-domain for further inference. Normally, this process involves copying to the I-domain a piece of information from the D-domain that is already verified. In conversation, stating verified information typically counts as informing the addressee.

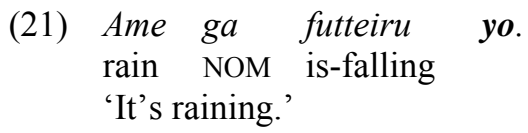

However, Takubo and Kinsui explain that utterance (21) does not simply inform the addressee, but it necessarily triggers addressee's inferences, e.g. taking an umbrella or cancelling the picnic. Unlike the case of ne, however, it is unclear how their explanation can apply to the usage of yo in soliloquy because of the lack of examples in their study that do not involve an addressee.

On the other hand, Inoue's (1997) explanation about yo is more comprehensible

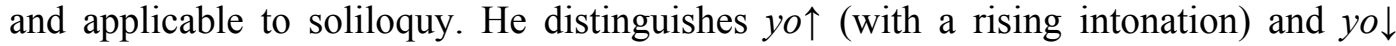
(with a level or a falling intonation). He contends that yo $\downarrow$ forces both the speaker and the addressee to re-evaluate the conversational and other relevant contexts in such a way that the conveyed proposition must be recognized as true. He illustrates his idea with the following examples:

$$
\begin{aligned}
& \begin{array}{lllll}
\text { a. Ano hito, } & \text { mada } & \text { anna koto } & \text { itteru yo } \downarrow \text {. } \\
\text { that } & \text { person still } & \text { such-a-thing is-saying }
\end{array} \\
& \text { (Message expected to be conveyed: Komatta mon da.) } \\
& \text { troublesome thing } \mathrm{COP} \\
& \text { 'That guy still says such a thing. (It's troublesome.)' } \\
& \text { b. Otoko wa tsurai yo } \downarrow \text {. (Maa, shikata ga nai naa.) } \\
& \text { man TOP hardship well cannot-help SFP } \\
& \text { 'A man's life is tough! (Well, it's useless to complain, though.)' }
\end{aligned}
$$

According to Inoue, the implicit messages in the parentheses in (22) are derived from the speaker's reconfirmation and reassessment of the relevance of each proposition.

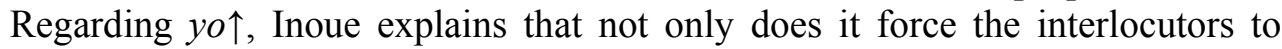
reconfirm the situation with the proposition deemed to be true, but it also obligates the addressee to consider his/her future act accordingly.

$$
\begin{aligned}
& \text { A: Inoue-san kara no fakusu todoitemasu ka? } \\
& \text { from GEN fax has-arrived } \\
& \text { 'Has a fax from Inoue come yet?' } \\
& \text { B: Todoitemasu yo } \uparrow \text {. ( Doo saremasu ka?) } \\
& \text { has-arrived how will-you-do } \\
& \text { 'Yes, it has. (What are you going to do with it?)' }
\end{aligned}
$$

This explanation accounts nicely for the situation represented in (6b), restated here as (24). 
$\begin{array}{lll}\text { (24) Kushiro } & \text { wa } & \text { samui } \\ & \text { TOP } & \text { is-cold }\end{array}$

'It's cold in Kushiro.'

With $y o \downarrow$, the speaker conveys an opinion such as "so I don't want to go there," whereas with $y o \uparrow$, the speaker asks whether the addressee still wants to go there. I believe that Inoue's explanation of yo $\uparrow$ is virtually identical with Takubo and Kinsui's analysis of yo, although Takubo and Kinsui do not give consideration to yo $\downarrow$.

The distinction between $y o \uparrow$ and $y o \downarrow$ can be derived from more general characteristics of intonation contour in discourse. Building on Pierrehumbert and Hirshberg's (1990) work, Katagiri (2007: 1321) asserts:

"An utterance-final rising intonation signals that the discourse unit currently being constructed continues past the utterance, and the next utterance to come will belong to the same unit as the current one. A falling intonation, on the other hand, signals that the discourse unit is being closed at the end of the utterance, and a new unit will be created from the next utterance. Simple as this continue/close distinction may be, we should note that in the case of interactive dialogues, we can distinguish two structural levels at which this signaling by intonation patterns operate, namely, the level of task structures and the level of discourse structures."

While intonation is irrelevant with ne (never falling in soliloquy), it plays a significant role with yo. Only yo $\downarrow$ can occur in soliloquy. This fact supports Inoue's analysis, wherein $y o \downarrow$ need not involve an addressee, but yo $\uparrow$ necessarily does.

One may wonder whether there is ever an overt (vocalized) inference that occurs after yo in soliloquy, or whether such inferences might be subvocalized or even just not be pursued. Let us further examine the occurrences of yo in our soliloquy data. In (16), the interrogative sentence Machigai denwa kayo 'Wrong number?' is followed by another interrogative Kimu-tte dare da yo 'Who's Kim?'. This sequence cannot be regarded as an instance of inference. Following the second sentence, the subject did not pursue the topic further and moved to a next topic. Although this sequence does not conform to our hypothesis, it should be noted that because both sentences are interrogative, it is an atypical sequence in soliloquy.

In (17), the subject said, Bosuton itte, hajimete shitta yo 'I learned it in Boston'. He then continued, 9,000-nin inno ka. Amerika de 9,000-nin te koto wa, igirisu to oosutoraria no ryuugakusee toka awasetara, 10,000 inno kana '9,000! If there are 9,000 in the U.S., there may well be 10,000 if those in England and Australia are combined'. This is a clear example of inferring.

The case (18) also supports our analysis; after Dango urenai yo, zettai 'Dango sweet dumplings won't sell, definitely', the subject continues to express his inferences:

(25) Te iu $k a$, rieki dasu niwa, ma, takoyaki wa ureru QUOT say or profit make for well octopus-ball TOP can-sell to shite, dango ga kanari urenai to mazui to. supposing NOM fairly not-sell if is-bad QUOT

'Or in order to make a profit, well, supposing octopus balls sell well, we'll get into trouble if dango won't sell enough.'

Regarding (20), unfortunately, un, yasui yo, sono hoo ga 'so, that one is cheaper' was 
the final utterance in her recording; therefore, we cannot use it to test our hypothesis. Although the samples in my soliloquy data are too few to make any reliable conclusion, the relevant ones are consistent with the analysis of yo proposed in this study.

Another issue that is worth exploring is why ne occurs very frequently in soliloquy, but yo rarely does so. If we postulate that the primary function of $n e$ is matching pieces of information and that of yo is as preparation, or a trigger, for inference, this highly skewed distribution becomes common sense. Let us discuss this issue by considering some of the major discoveries in memory research in the field of cognitive science.

Human life involves constant learning, i.e. acquisition of various kinds and pieces of knowledge from one's surroundings. To account for how humans manage such a stream of incoming information, Atkinson and Shiffrin (1968) proposed a highly influential model of memory. In their model, the first component is called a sensory register, which stores incoming sensory signals (e.g. sounds, images) but holds them for less than a second. The second component is referred to as a short-term store, holding information in one's awareness, which will be lost in approximately 30 seconds if it is not rehearsed or reactivated. The third component, called long-term store, has an unlimited capacity; information stored there can last one's lifetime.

This type of memory model hypothesizes that when a new piece of information is acquired, it is temporarily stored in working memory. ${ }^{10}$ Some of the information stored in working memory then becomes encoded, or, to use a neuroscience term, consolidated into long-term memory. Later, when the stored information is recalled/retrieved into working memory in a new context, it merges with a new piece of information and modifies itself.

There is abundant evidence supporting the idea that at some stage during the information processing, retention, or retrieving, people check on the consistency between the newly acquired information and the relevant knowledge pre-existing in their long-term memory.

The hitherto reported experimental results demonstrate that matching is common place in memory manipulation by humans. Therefore, if $n e$ is associated with matching, its frequent occurrences in soliloquy should not be surprising. On the other hand, triggering an inference, the postulated function of yo in the present study, is a far more complicated activity. Furthermore, all instances of inference seem to involve matching of information. That is, matching two pieces of information is an indispensable part of inference, but not vice versa. This explains why ne appears abundantly in soliloquy, but yo does not.

\section{Concluding remarks}

Following a brief summary of previous works on the Japanese sentence-final particles ne and yo, this paper analyzed these particles as they occur in the

\footnotetext{
${ }^{10}$ Atkinson and Shiffrin (1968: 83) construe working memory as "In our thinking we tend to equate the short-term store with 'consciousness,' that is, the thoughts and information of which we are currently aware can be considered part of the contents of the short-term store. ... Because consciousness is equated with the short-term store and because control processes are centered in and act through it, the short-term store is considered a working memory: A system in which decisions are made, problems are solved and information flow is directed."
} 
experimentally-obtained soliloquy data. Both particles have traditionally been described almost exclusively in terms of information sharing, or a lack thereof, between speaker and addressee. Because these particles can also occur in soliloquy, where no addressee distinct from the speaker him/herself is involved, most hitherto proposed analyses were found inadequate. For ne, the present study endorses Takubo and Kinsui's Discourse Management Model. For yo, Inoue's account is vindicated.

Experimental data from psychology imply that native speakers first acquire the particles $n e$ and yo as communicative means, and then extend their uses to their mental activities, as Vygotsky conjectures. Although this direction of acquisition appears to be conclusive, the exact mechanism requires further investigations.

The fact that $n e$ occurs in soliloquy as frequently as it does in dialogue, while yo does not, reveals that, if the characterization proposed in this chapter of these particles is valid, matching of two pieces of information is a far more routine mental activity than inferring is.

To my knowledge, this study is a first serious attempt to utilize soliloquial data for linguistic investigation. It is undeniable that language is by far the most effective means for general communication. Therefore, it is reasonable to investigate linguistic devices with respect to communicative intentions. However, as we have witnessed through the data provided in this paper, such devices can be used in a pre-communicative stage, i.e. during the preparation phase of interpersonal utterances. I hope that soliloquial data will draw overdue attention to, and deepen our understanding of, our thinking and communication revealed by language.

\section{References}

Atkinson, Richard, and Richard Shiffrin (1968) Human memory: A proposed system and its control processes. In K. Spence and J. Spence (eds.), The psychology of learning and motivation. New York: Academic Press, pp. 89-195.

Bakhtin, Mikhail (1984) Problems of Dostoevsky's poetics. Minneapolis: University of Minnesota Press.

Cheng, Changhao (1987) Shuujoshi [Sentence final particles]. Nihongogaku 6: 93-109.

Clancy, Patricia (1986) The acquisition of Japanese. In D. Slobin (ed.), The cross-linguistic study of language acquisition. Hillsdale, NJ Lawrence Erlbaum Associates, pp. 373-524.

Cook, Haruko (1990) The sentence-final particle ne as a tool for cooperation in Japanese conversation. In Hoji, Hajime (ed.), Japanese Korean Linguistics. Stanford: CSLI, pp. 29-44.

Cook, Haruko (1992) Meanings of non-referential indexes: A case study of Japanese sentence-final particle ne. Text 12: 507-539.

Hirose, Yukio (1995) Direct and indirect speech as quotations of public and private expression. Lingua 95: 223-238.

Inoue, Masaru (1997) Moshi moshi, kippu o otosaremashita yo [Hi, you've dropped a ticket]. Gekkan Gengo 26: 62-67.

Iwasaki, Takashi (1995) 'Node' to 'kara' [node and kara]. In T. Miyajima and Y. Nitta (eds.), Nihongo ruigihyoogen no bunpoo II. Tokyo: Kurosio, pp. 506-513. 
Izuhara, Eiko (2003) Shuujoshi 'yo', 'yone', 'ne' saikoo [The sentence-final particles yo, yone, and ne revisited]. The Journal of Aichi Gakuin University 51: 1-15.

Jakobson, Roman (1960/1987) Linguistics and poetics. In Language in literature. Cambridge, MA: Harvard University Press, pp. 62-94.

Kamio, Akio (1994) The theory of territory of information: The case of Japanese. Journal of Pragmatics 21: $67-100$.

Katagiri, Yasuhiro (1995) Shuujoshi ni yoru taiwa choosei [Managing a conversation by sentence-final particles]. Gekkan Gengo 24: 38-45.

Katagiri, Yasuhiro (2007) Dialogue functions of Japanese sentence-final particles 'Yo' and 'Ne'. Journal of Pragmatics 39: 1313-1323.

Kato, Shigehiro (2001) Bunmatsu joshi 'ne' 'yo' no danwa koosei kinoo [The constructive functions of the sentence-final particles ne and yo in discourse]. Toyama Daigaku Jinbun Gakubu Kiyoo 35: 31-48.

Kinsui, Satoshi, and Yukinori Takubo (1998) Danwa kanri riron ni motozuku 'yo, ne, yone' no kenkyuu [A study of yo, ne, yone in the Discourse Management Theory]. In S. Doshita, et al. (eds.), Onsei ni yoru ningen to kikai no taiwa. Tokyo: Ohmsha, pp. 257-270.

Kokuritsu Kokugo Kenkyujo (1955) Danwago no jittai [A study of discourse function words]. Tokyo: Kokuritsu Kokugo Kenkyujo.

Kuroda, Shigeyuki (1979/1992) (Ko) so a ni tsuite [On ko, so, a demonstratives]. In S. Kinsui \& Y. Takubo (eds.), Shijishi. Tokyo: Hituzi Syobo, pp. 91-104.

Maynard, Senko (1991) Pragmatics of discourse modality: A case of da and desu/masu forms in Japanese. Journal of Pragmatics 15: 551-582.

Maynard, Senko (1993) Discourse modality: Subjectivity, emotion and voice in the Japanese language. Amsterdam: John Benjamins Publishing Company.

Maynard, Senko (1997) Japanese communication: Language and thought in context. Honolulu: University of Hawai'i Press.

Moriyama, Shin (1998) Shuujoshi 'na' to 'ne' no imi, yoohoo no chigai ni tsuite [On the meanings and functions of the sentence-final particles ne and yo]. The Korean Journal of Japanology 41: 171-187.

Nitta, Yoshio (1991) Ishi no hyoogen to kikite sonzai [Expressions of the speaker's will and the presence of a listener]. Kokugogaku 165: 1-13.

Ohso, Mieko (1986) Goyoo-bunseki I 'kyoo wa ii tenki desu ne.' - 'Hai, soo desu.' [An error analysis: 'Today's a good day, isn't it?' 'Yes, it is']. Nihongogaku 5: 91-95.

Okamoto, Shigeko (1999) Situated politeness: Coordinating honorific and non-honorific expressions in Japanese conversations. Pragmatics 9: 51-74.

Okubo, Ai (1967) Yooji gengo no hattatsu [Child language development]. Tokyo: Tokyodo.

Ono, Susumu, and Hiroshi Nakagawa (1997) Semantics of Japanese sentence final particles represented by hierarchal memory model - about YO NE NA ZO ZE. Ninchi Kagaku 4: 39-57.

Piaget, Jean (1923/2002) Language and thought of the child. London: Routledge.

Pierrehumbert, Janet, and Julia Hirshberg (1990) The meaning of intonational contours in the interpretation of discourse. In P. Cohen, J. Morgan \& M. Pollack (eds.), Intentions in communication. 
Cambridge, MA: MIT Press, pp. 271-311.

Shinzato, Rumiko (2004) Some observations concerning mental verbs and speech act verbs. Journal of Pragmatics 36: 861-882.

Shirakawa, Hiroyuki (1995) Riyuu o arawasanai 'kara' [Kara for indicating a reason]. In Yoshio Nitta (ed.), Fukubun no kenkyuu I . Tokyo: Kurosio, pp. 180-219.

Shirakawa, Hiroyuki (2001) Setsuzoku joshi 'shi' no kinoo [The function of the conjunctive particle shi]. In Nakau Minoru Kyooju Kanreki Kinen Ronbunshuu Henshuuiinkai (ed.), Imi to ninchi no intaafeisu. Tokyo: Kurosio, pp. 825-836.

Suzuki, Mutsumi (1997) Nihongo-kyooiku ni okeru teineitai-sekai to futsuutai-sekai [The polite style and the plain style in Japanese-language education]. In Y. Takubo (ed.), Shiten to gengo-koodoo. Tokyo: Kurosio, pp. 45-76.

Takubo, Yukinori, and Satoshi Kinsui (1997) Discourse management in terms of mental spaces. Journal of Pragmatics 28: 741-758.

Teramura, Hideo (1982) Nihongo no shintakusu to imi II. Tokyo: Kurosio.

Teramura, Hideo (1984) Heiretsuteki keizoku to sono tookatsu meidai: Mo, shi, shikamo no baai [Parallel conjunction and its unified proposition: The case of mo, shi, and shikamo]. Nihongogaku 3: 67-74.

Tsubone, Yukari (1996) Shuujoshi, setsuzokujoshi to shite no "mono" no imi. Nihongo Kyoiku 91: 37-48.

Usami, Mayumi (1995) Danwa-reberu kara mita keigo shiyoo: Supiichi-reberu-shifuto seiki no jooken to kinoo [Conditions for speech-level shift occurrence in Japanese discourse]. Gakuen 662: 27-42.

Uyeno, Tazuko (1971) A study of Japanese modality: A performance analysis of sentence particles. Unpublished dissertation, University of Michigan.

Uyeno, Tazuko (1972) Shuujoshi to sono shuuhen [Sentence-final particles and their neighbors]. Nihongo Kyooiku 17: 62-77.

Vygotsky, Lev (1934/1986) Thought and language. Cambridge, MA: MIT Press.

Washi, Rumi (1997) Shuujoshi to hatsuwa-ruikei: Tokyo-go shuujosi 'wa' to 'na' no danwa ni okeru hataraki [Sentence-final particles and discourse types: The functions of $w a$ and $n a$ in the Tokyo dialect]. Nihongo Nihonbunka Kenkyuu 7: 65-79.

Watamaki, Toru (1997) Jiheishooji ni okeru kyookan kakutoku hyoogen joshi 'ne' no shiyoo no ketsujo: Jirei kenkyuu [Lack of the particle-ne in the conversational speech of a child with autism: A case study]. Hattatsu Shoogai Kenkyuu 19: 146-157.

YOKO HASEGAWA (Ph.D. University of California at Berkeley) is associate professor of Japanese Linguistics in the Department of East Asian Languages and Cultures at the University of California at Berkeley. Her research focuses on cognitive linguistics, semantics, pragmatics, and translation studies. Her publication includes $A$ Study of Clause Linkage: The Connective - TE in Japanese (CSLI/Kurosio 1996), Nihongo kara mita nihonjin: Shutaisei no gengogaku (with Yukio Hirose, Kaitakusha, 2010), and A Course in Japanese Translation (Routledge, forthcoming).

Address: EALC, 3413 Dwinelle Hall, Berkeley, CA 94720-2230, United States. E-mail: hasegawa@berkeley.edu 